\title{
Multi-Objective Design of a Close-Coupled Inductor for a Three-Phase Interleaved 140kW DC-DC Converter
}

\author{
J. Zwysen, R. Gelagaev, J. Driesen \\ Department ESAT, Research Group ELECTA \\ KU Leuven, Leuven, Belgium \\ Email: jeroen.zwysen@esat.kuleuven.be
}

\author{
S. Goossens, K. Vanvlasselaer, W. Symens \\ FMTC, Flanders' Mechatronics Technology Centre \\ Leuven, Belgium \\ Email: kris.vanvlasselaer@fmtc.be
}

\author{
B. Schuyten \\ Sirris, The Collective Center for the Belgian technological industry \\ Leuven, Belgium
}

\begin{abstract}
A multi-objective design procedure is applied to the design of a close-coupled inductor for a three-phase interleaved $140 \mathrm{~kW}$ DC-DC converter. For the multi-objective optimization, a genetic algorithm is used in combination with a detailed physical model of the inductive component. From the solution of the optimization, important conclusions about the advantages and disadvantages of using close-coupled inductors compared to separate inductors can be drawn.
\end{abstract}

Keywords-multi-objective optimization, close-coupled inductor, DC-DC converter, genetic algorithm

\section{INTRODUCTION}

In this paper, a new topology for an existing DC-DC converter, consisting of three interleaved half bridges with separate inductors, is investigated. A schematic of the existing and proposed converter is shown on the left and right of Fig. 1. In the new topology, a close-coupled inductor is used. This could reduce the total volume and power dissipation of the inductive components of the converter [1][2][3].

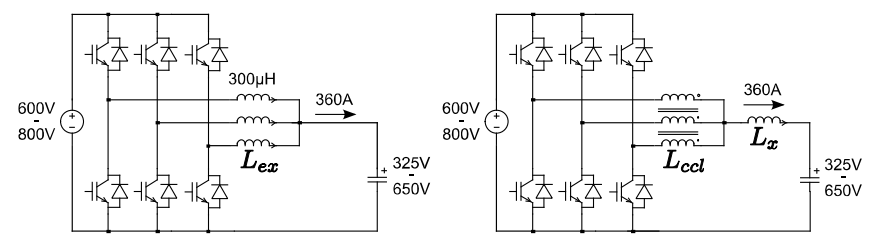

Fig1. Existing and new topology

The DC-DC converter is used to transfer energy from a high voltage DC bus to an array of supercapacitors. The DC bus is connected to the grid through a passive three-phase rectifier and to a motor through a three-phase inverter. The primary function of the DC-DC converter is to store braking energy of that motor. A secondary use is to minimize harmonics in the current drawn from the grid due to cyclic variations in the load attached to the motor. A similar system can be found in a hybrid drive system for an industrial truck developed by Honda [3].
To design the inductors for the new topology, an extensive physical model of the inductors is made. The model takes into account temperature dependent saturation, leakage flux, skin and proximity effect in the windings and induced current due to fringing flux. Afterwards a multi-objective optimization uses this model to find the optimal inductors, minimizing both volume and power dissipation. With these optimal designs, the advantages of using the new topology can be assessed.

While this paper focuses on a specific example, the method used in the paper can be easily adapted and applied to the design of other type of inductors such as transformers. Subtasks are solved using free to use software such as LTSpice, FastCap and FEMM. References are given to expand on details that could not be included in this paper.

\section{THEORETICAL COMPARISON}

The main advantage of the new topology, shown in Fig. 1 on the right, is that, for $\mathrm{L}_{\mathrm{ccl}}$, the $\mathrm{DC}$ component of the fluxes generated in every phase cancel each other out in the magnetic core. This is shown in Fig. 2.

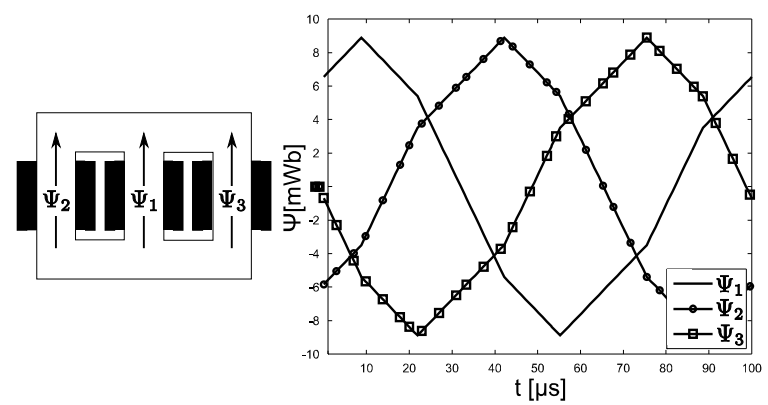

Fig. 2 Close-coupled inductor and waveforms fluxes through core legs

This means that the magnetic material will be used bidirectionally, both positive and negative fluxes are induced, and the materials can have a lower saturation flux, $\mathrm{B}_{\text {sat }}$. While the original inductors, $\mathrm{L}_{\mathrm{ex}}$, use an amorphic alloy, Metglas 2605SA1, a ferrite core will be used for the design of $\mathrm{L}_{\mathrm{ccl}}$. 
Ferrite has less losses, see table 1, and is available in a variety of different sized segments. That way, the dimensions of the core can be chosen more freely.

TABLE I. COMPARISON OF METGLAS AND EPCOS N95

\begin{tabular}{rccl}
\hline & $\begin{array}{c}\text { Metglas } \\
\text { 2605SA1 }\end{array}$ & $\begin{array}{c}\text { Epcos } \\
\text { N95 }\end{array}$ & \\
\hline $\mathbf{p}_{\mathbf{v}}, \mathbf{1 0 k H z}^{*}$ & 220 & 60 & {$\left[\mathrm{~kW} / \mathrm{m}^{3}\right]$} \\
$\mathbf{p}_{\mathbf{v}}, \mathbf{3 0 k H z}^{*}$ & 1080 & 250 & {$\left[\mathrm{~kW} / \mathrm{m}^{3}\right]$} \\
B $_{\text {sat }}$ & 1.5 & 0.400 & $\mathrm{~T}$ \\
\hline & *Using Steinmetz, $25^{\circ} \mathrm{C}, 300 \mathrm{mT}$ &
\end{tabular}

To keep the maximum output ripple current going to the supercapacitors the same in the new topology, the output inductor $\mathrm{L}_{\mathrm{x}}$ should have an inductance equal to one third of the inductance of $\mathrm{L}_{\mathrm{ex}}$ [2]. But because the maximum current through $\mathrm{L}_{\mathrm{x}}$ is almost three times as high, the maximum flux, generated in the magnetic core of $\mathrm{L}_{\mathrm{x}}$, will be about equal to the flux generated in $\mathrm{L}_{\mathrm{ex}}$. This means that a magnetic material with comparable saturation flux should be used. But the stored magnetic energy, $\mathrm{Li}^{2} / 2$, is higher in $\mathrm{L}_{\mathrm{x}}$, indicating that $\mathrm{L}_{\mathrm{x}}$ will be bigger than $\mathrm{L}_{\mathrm{ex}}$ when the same material is used. Furthermore, the fundamental frequency of the ripple current through $\mathrm{L}_{\mathrm{x}}$ is three times higher than in $\mathrm{L}_{\mathrm{ex}}$ which leads to higher winding and core losses.

Table 2 summarizes the requirements of both $\mathrm{L}_{\mathrm{ccl}}$ and $\mathrm{L}_{\mathrm{x}}$ compared to the existing inductances, $\mathrm{L}_{\mathrm{ex}}$, used in the existing topology. This is derived from analytical formulas that can be found in [2].

TABLE II. REQUIREMENTS FOR $\mathrm{L}_{\mathrm{CCL}}$ AND $\mathrm{L}_{\mathrm{X}}$ COMPARED TO $\mathrm{L}_{\mathrm{EX}}$

\begin{tabular}{rcccc}
\hline & $\mathbf{L}_{\mathbf{e x}}$ & $\mathbf{L}_{\mathbf{C C L}}$ & $\mathbf{L}_{\mathbf{X}}$ & \\
\hline Inductance, $\mathbf{L}$ & 300 & $\mathrm{f}(\Delta \mathrm{I})$ & 100 & $\mu \mathrm{H}$ \\
Max. Current & 153 & $\mathrm{f}(\mathrm{L})$ & 371 & $\mathrm{~A}$ \\
Max. Current Ripple, $\Delta \mathbf{I}$ & 67 & $\mathrm{f}(\mathrm{L})$ & 22 & $\mathrm{~A}$ \\
Fundamental Frequency Flux & 10 & 10 & 30 & $\mathrm{kHz}$ \\
Max. Flux Windings & 46 & 8.9 & 37 & $\mathrm{mWb}$ \\
Max. Flux Windings Ripple & 20 & 18 & 2.2 & $\mathrm{mWb}$
\end{tabular}

From Table 2 and from previous discussions, it is clear that a theoretical comparison alone is not sufficient to get an idea of the achievable volume and power dissipation loss. For this, a detailed physical model of the inductive components is required.

\section{PHYSICAL MODEL}

The physical model for $\mathrm{L}_{\mathrm{ccl}}$ and $\mathrm{L}_{\mathrm{x}}$ is used to calculate power loss and volume. To do so, both the flux distribution in the magnetic core and the current distribution in the windings need to be determined. Saturation of the core, leakage flux, skin and proximity effect and fringing flux around the air gaps are important effects which will be modeled. Another requirement is that the calculations are fast, since it will be evaluated thousands of times by the optimization algorithm, explained in chapter IV. Fig. 3 shows the structure of the physical model and each part will be explained in the next chapters. In chapter III.E, it will be explained that the model will not be very accurate for $\mathrm{L}_{\mathrm{x}}$ which is why that inductor will be designed independently by Spica and only $\mathrm{L}_{\mathrm{ccl}}$ will be designed using the procedure described in this paper.

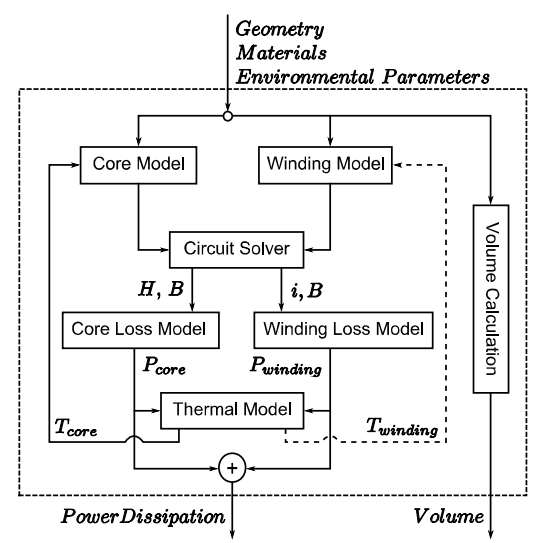

Fig. 3 Structure of physical model for $\mathrm{L}_{\mathrm{ccl}}$

\section{A. Geometry and Input Parameters}

Input parameters for the physical model include geometrical parameters to describe the core, windings and cooling block dimensions. The core consists of two E-cores with an air gap in each leg of equal length. The material, used to fill the air gap, is FR-4. The $\mathrm{N}_{\mathrm{w}}$ copper windings are foil windings with a width of $\mathrm{w}_{\mathrm{c}}$ and Nomex410 for electric isolation. The space between the windings and the core legs, parameter $d_{c w}$, is filled with FR-4. A water cooling system is present in the converter above the inductors. Two identical aluminium blocks, on each side of the core, transfer heat from the core to the water cooling system. Between the core and aluminium cooling block, $2 \mathrm{~mm}$ thermal foil is used. The geometry of the core and cooling blocks are shown in Fig. 4.

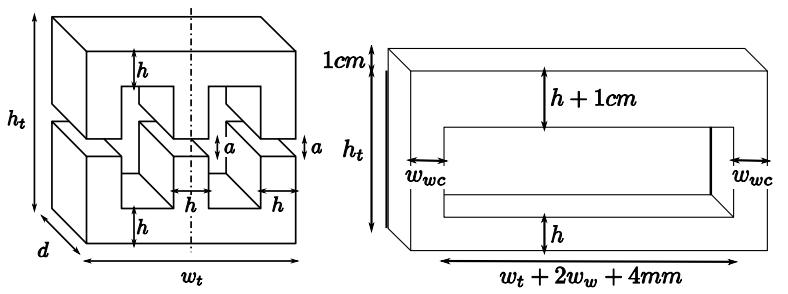

Fig. 4 Geometry parameters of the core and water cooling blocks for $\mathrm{L}_{\mathrm{ccl}}$ ( $\mathrm{w}_{\mathrm{w}}$ is the total width of the windings, including isolation and $\mathrm{d}_{\mathrm{cw}}$ )

Another parameter indicates which magnetic core material is used. The materials under consideration are some of the ferrites from Epcos: N27, N41, N49, N51, N72, N87, N92, N95 and N97. Environmental parameters are the water temperature in the water cooling system and the air temperature inside the converter.

\section{B. Core Model}

The core model will be used to determine the flux distribution in the core. To this end, a reluctance model of the magnetic core is made [4][5]. Saturation is modeled by 
approximating it with the Langevin function [6]. Hysteresis and eddy-current effects are not modeled as the hysteresis surface of ferrite is small and the electric resistivity is high.

For this application, the magnetic coupling between the windings is of critical importance as only a good coupling ensures the cancellation of DC flux in the core. That is why an accurate estimation of the reluctance of the corner and $\mathrm{T}$ junction segments in the core is required. Even more important for coupling is modeling the leakage flux by including leakage flux reluctances in the model. How this is done is described in [7][8].

\section{Winding Model}

In the foil windings, skin effect and proximity results in higher current densities towards the edges of the conductors. This generates more power dissipation in the copper and both effects need to be taken into account.

Fringing flux, flux leaving the core leg at the air gap, induces current in the copper windings. This causes extra power dissipation, concentrated in the copper closest to the air gap.

Both effects are simulated using FEMM, a program using the finite element method for simulation of magnetic problems in the frequency domain. Two simulations are necessary: one to determine the current distribution due to skin and proximity effect, $\mathrm{J}_{\mathrm{s} \& \mathrm{p}}$, and another one for determining the induced current due to fringing flux, $\mathrm{J}_{\mathrm{f}}$. Both simulations are shown in Fig. 5. They are executed only for the fundamental frequency, $\mathrm{f}_{0}$, of $10 \mathrm{kHz}$. Higher harmonics also contribute to extra power loss but their contribution appeared negligible.

In the first simulation, for skin and proximity effect, the conductors are modeled individually and a current of $1 \mathrm{~A}$ is sent through every conductor. The air gap in the core leg can be neglected which speeds up the simulation without losing much of the accuracy of the solution. In a second simulation, for the induced current due to the fringing flux, the conductors are modeled as one solid copper conductor [9]. Now the air gap has to be modeled and a flux of 1T is sent through the core leg.

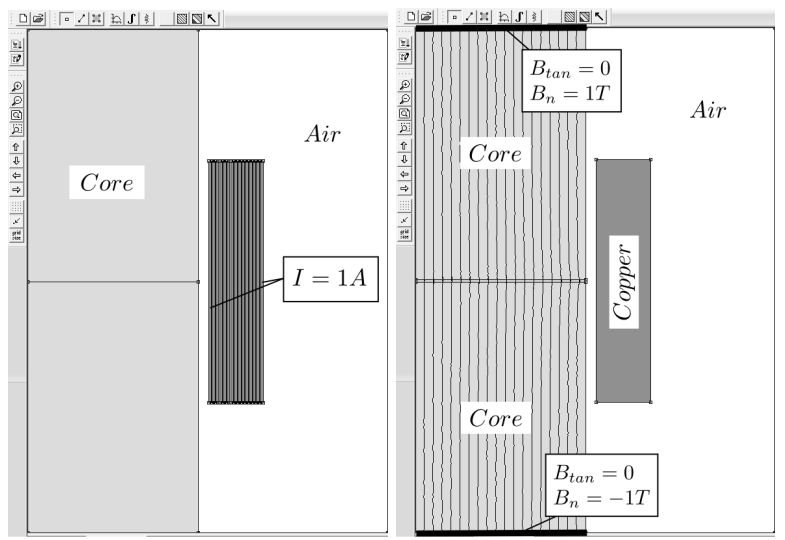

Fig. 5 FEMM simulations for skin and proximity effect, and fringing flux effect

The resulting current distributions, $\mathrm{J}_{\mathrm{s} \& \mathrm{p}}$ and $\mathrm{J}_{\mathrm{f}}$, are shown in Fig. 6 for the fundamental frequency of $10 \mathrm{kHz}$. They are saved in the winding model to be used later for calculation of the power dissipation in the conductors.
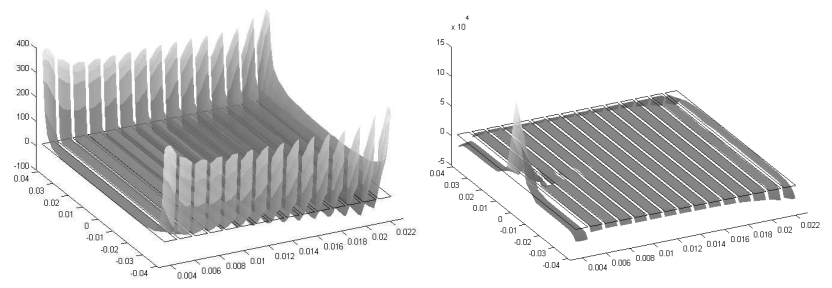

Fig. 6 Current distributions in windings, $\mathrm{J}_{\mathrm{s} \& \mathrm{p}}$ (left) and $\mathrm{J}_{\mathrm{f}}$ (right)

\section{Circuit Solver}

The circuit solver uses both core and winding models to determine currents, magnetic induction and magnetic fields, in the circuit and in the magnetic core. Both models are implemented in LTSpice, a time domain simulator based on SPICE. For the winding model, only a resistance to represent the DC resistance of the copper is used because the $\mathrm{AC}$ resistance, due to skin and proximity effect, is difficult to take into account in a time domain simulator. Also, the IGBT half bridges are replaced by pulsed voltage sources to speed up simulation. The circuit that is simulated is shown in Fig. 7.

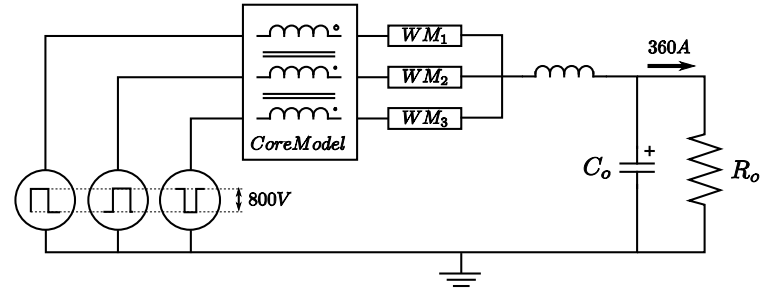

Fig. 7 Circuit that is simulated in the time domain using LTSpice

The circuit is simulated in the operating point with maximum output ripple current as this ripple is limited to $22 \mathrm{~A}$. Therefore, the DC bus voltage is set to $800 \mathrm{~V}$ and the duty cycle to $50 \%$. So the output resistance, $\mathrm{R}_{0}$, is set to $400 \mathrm{~V} / 360 \mathrm{~A}$. The output capacitor, $\mathrm{C}_{0}$, is set to $1 \mathrm{mF}$ to limit the voltage ripple at the low voltage side.

\section{E. Core Loss Model}

To calculate the losses in the core, the improved generalized Steinmetz equation is used [10][11]. The expression is given in (1) and uses the magnetic inductance B, calculated by the circuit simulator. The parameters, $\alpha, \beta$ and $\mathrm{k}$, in this equation are also used in the normal Steinmetz equation for sinusoidal excitations. They are obtainable from datasheets, given by the manufacturer of the magnetic material. The result is the specific power dissipation, $\mathrm{p}_{\mathrm{v}}\left[\mathrm{W} / \mathrm{m}^{3}\right]$, in the magnetic material.

$$
\begin{aligned}
& p_{v}=f_{0} \int_{0}^{f_{0}^{-1}} k_{i}\left|\frac{d B}{d t}\right|^{\alpha}(\Delta B)^{\beta-\alpha} d t \\
& \text { with } k_{i}=\frac{k}{(2 \pi)^{\alpha-1} \int_{0}^{2 \pi}|\cos \theta|^{\alpha} 2^{\beta-\alpha} d \theta}
\end{aligned}
$$

Although equation (1) is valid for nonsinusoidal fluxes, it is not valid for fluxes with a large DC offset [11]. For this reason, 
the output inductor $\mathrm{L}_{\mathrm{x}}$ will be designed by Spica and not with the optimization technique described in this paper.

\section{F. Winding Loss Model}

The circuit simulator calculates the total current running through the conductors, as well as the magnetic induction B through each core leg, in the time domain. In a first step, the DC component, harmonic number h equal to 0 , and the $10 \mathrm{kHz}$ component, harmonic number $\mathrm{h}$ equal to 1 , of this current and magnetic induction is calculated using (2).

$$
X(h)=f_{0} \int_{0}^{f_{0}^{-1}} x(t) e^{-j 2 \pi h f_{0}} d t
$$

For both DC and at $10 \mathrm{kHz}$ the current distributions, due to skin and proximity effect and due to fringing flux from the magnetic induction B in the core leg, are known. So the current density inside foil windings is given by (3).

$$
J_{h}(h, \vec{p})=I(h) \cdot J_{s \& p}(h, \vec{p})+B(h) \cdot J_{f}(h, \vec{p})
$$

In (3), I(h) and $\mathrm{B}(\mathrm{h})$ are the $\mathrm{h}$ 'th harmonic component of the current running through the windings and the magnetic induction in the core leg around which the winding is fold. This current density in the frequency domain is transferred back to the time domain using (4).

$$
J(t, \vec{p})=J_{h}(0, \vec{p})+2 \mathfrak{R}\left(\sum_{h=1}^{H} J_{h}(h, \vec{p}) e^{j 2 \pi h f_{0} t}\right)
$$

Because we only took the first harmonic into account, as explaint earlier, $\mathrm{H}=1$ in (4). And then finally the power loss in each conductor of the windings, $\mathrm{p}_{\mathrm{c}, \mathrm{i}}[\mathrm{W} / \mathrm{m}]$, can be calculated by (5) where $\sigma_{\mathrm{Cu}}$ is the conductivity of copper.

$$
p_{c, i}=f_{0} \int_{A_{c, i}} \int_{0}^{f_{0}^{-1}} \frac{J(t, \vec{p})^{2}}{\sigma_{C u}} d t d \vec{p}
$$

\section{G. Thermal Model}

For the thermal model, an equivalent electric circuit is made. Current sources represent power dissipation and voltages represent temperatures. Resistances represent conductive or convective thermal resistances.

Conductive thermal resistances can be calculated using (6), where 1 is the length of the conductive path, A is the crosssectional area and $\mathrm{k}$ is the thermal conductivity of the material. The latter is given for different materials in table 3 .

$$
R=\frac{\Delta T}{P}=\frac{l}{k A}
$$

TABLE III. THERMAL CONDUCTIVITIES

\begin{tabular}{cccc}
\hline & $\mathbf{k}[\mathbf{W} / \mathbf{m K}]$ & & $\mathbf{k}[\mathbf{W} / \mathbf{m K}]$ \\
\hline Ferrite & 3.5 & Nomex410 & 0.14 \\
Copper & 400 & FR-4 & 0.25 \\
Aluminium & 250 & Thermal foil & 3 \\
\hline
\end{tabular}

Convective thermal resistances for natural convection at vertical and horizontal surfaces can be found in [12]. They are dependent on temperature which makes the resulting equivalent circuit non-linear.

The water cooling, connected to the top of the aluminium cooling blocks, is modeled by planes of constant temperature.

After solving this non-linear thermal problem, the resulting temperatures are fed back to the core model because the magnetic properties of the core are temperature dependent. This process is repeated until the temperatures stabilizes.

\section{GENETIC AlgORITHM}

Since both power dissipation as well as volume need to be optimized for the close-coupled inductor $\mathrm{L}_{\text {ccl }}$, a multi-objective optimization is required. A genetic algorithm is well suited for the problem as it can easily handle a mix of discrete and continuous parameters [13]. The algorithm will be based on constrained NSGA-II [14] and an outline is shown in Fig. 8.

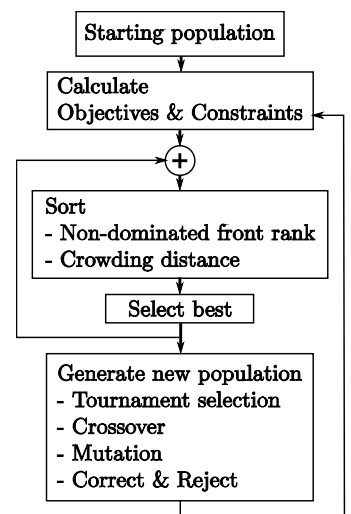

Fig. 8 Outline of the genetic algorithm used for multi-objective optimization

Every individual is represented by ten parameters, nine of which are related to geometrical dimensions and one to identify the magnetic core material. The parameters are given in Table 4. Combinations of geometrical dimensions are used to limit the number of individuals that represent non-physical geometries such as when $h$ is bigger than $h_{t}$ in Fig. 4 . The limits on these parameters are also given in table 4 .

\section{TABLE IV 10 PARAMETERS FOR INDIVIDUAL IN GENETIC ALGORITHM}

\begin{tabular}{ccccc}
\hline parameter & limits & $\boldsymbol{\alpha}$ & $\boldsymbol{\sigma}$ & final design \\
\hline$d$ & $3 \mathrm{~cm} \ldots 20 \mathrm{~cm}$ & 0.2 & $1 \mathrm{~cm}$ & $7.9 \mathrm{~cm}$ \\
$\frac{h_{t}-2 h}{d}$ & $1 \ldots 20$ & 0.2 & 0.5 & 1.04 \\
$d h$ & $10 \mathrm{~cm}^{2} \ldots 400 \mathrm{~cm}^{2}$ & 0.2 & $10 \mathrm{~cm}^{2}$ & $29 \mathrm{~cm}^{2}$ \\
$d h / a$ & $0.1 \mathrm{~m} \ldots 5 \mathrm{~m}$ & 0.2 & $0.3 \mathrm{~m}$ & $3.2 \mathrm{~m}$ \\
$N_{w}$ & $1 \ldots 50$ & 0.5 & 3 & 15 \\
$d_{c w} / a$ & $1 \ldots 5$ & 0.2 & 1 & 2.78 \\
$w_{c}$ & $1 \mathrm{~mm} \ldots 5 \mathrm{~mm}$ & 0.2 & $0.5 \mathrm{~mm}$ & $1 \mathrm{~mm}$ \\
$w_{w c}$ & $1 \mathrm{~cm} \ldots 10 \mathrm{~cm}$ & 0.2 & $1 \mathrm{~cm}$ & $1.28 \mathrm{~cm}$ \\
$d_{w c} / w_{w}$ & $1 \ldots 5$ & 0.2 & 0.5 & 1 \\
mat & $1 \ldots 9$ & 0 & 2 & 8 \\
\hline
\end{tabular}


For all individuals in the population, the object function, which is the physical model, is used to calculate the two objectives: volume and power dissipation. Afterwards, some multiple constraints have to be evaluated: the output ripple current should remain lower than $22 \mathrm{~A}$, the temperatures in the core and copper should be lower than the maximum allowable temperatures of both the core and the isolation between the copper. For safety, only $75 \%$ of these maximum temperatures is allowed. The individuals are then grouped together with the individuals from the previous generation and they are sorted according to their non-dominated front rank and their crowding distance [14].

From the sorted list, individuals are selected using binary tournament selection. New individuals are generated from these selected individuals using intermediate crossover and Gaussian mutation. The chance of crossover is set to $80 \%$ and chance of mutation is set to $30 \%$. The exploration coefficient, $\alpha$, used in intermediate crossover, is given in table 4 for every parameter. The standard deviation for Gaussian mutation, $\sigma$, is also given in table 4 .

A population size of 100 individuals is used. One evaluation of the physical model uses, on average, five minutes of computation time (Matlab R2012a, Intel Core i7-2760QM). Since about 90 iterations where required to obtain the optimal solutions, this would take about a month on one computer. But the 100 evaluations of the physical model in one iteration can be done in parallel on multiple computers. By using 40 computers in parallel, 92 iterations could be completed in under 20 hours. The individuals of the last iteration are shown in Fig. 9 in the objective space.

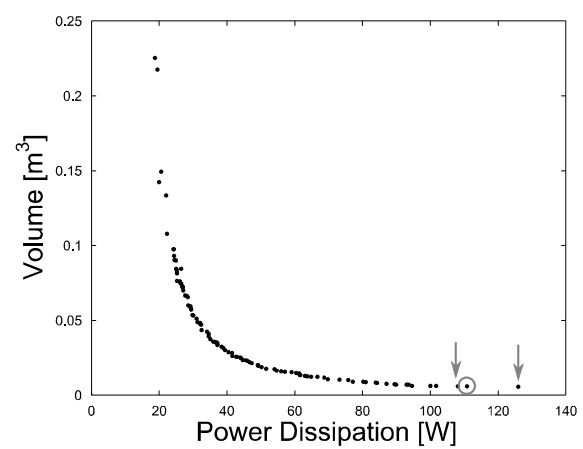

Fig. 9 Individuals of the last, 92th, iteration in the objective space

\section{SOLUTION}

\section{A. Sensitivity Analysis}

Not all solutions from Fig. 9 are acceptable however. A sensitivity analysis is required to know the effect of geometrical imperfections, deviating air and water temperatures and errors in the calculation of the power dissipation on the temperatures inside the core and in the windings. From this analysis, two individuals are excluded as possible solutions. These are indicated by an arrow in Fig. 9.

\section{B. Unbalance Analysis}

Another analysis that is important in this case, is an unbalance analysis. In this analysis, the effect of unbalanced phase currents is investigated. The total current is set to the maximum current of $360 \mathrm{~A}$, but a one-phase unbalance is introduced by the controller. The maximum magnetic induction, $\mathrm{B}$, in the core is calculated for different levels of unbalance. To speed up the analysis, a linear core model without saturation is used. An example of the result of the analysis on the individual, indicated in Fig. 9 by a circle, is shown in Fig. 10.
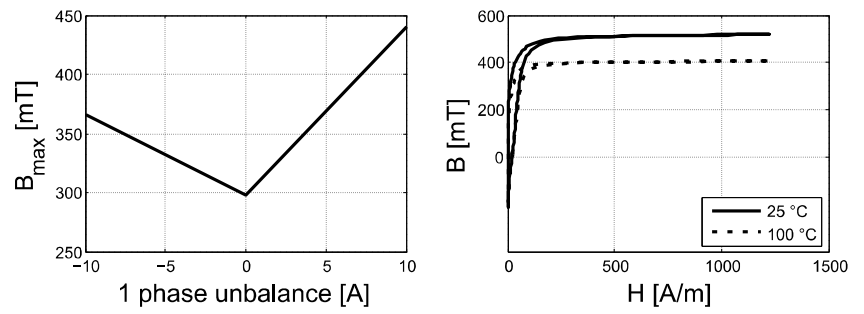

Fig. 10 Unbalance analysis of individual, indicated in Fig. 9 by a circle

From Fig. 10, it can be seen that the unbalance must be kept under 4A. This means that both the measurement and control system must be able to keep the unbalance under this limit. This is a disadvantage of using a close-coupled inductor instead of individual inductors. A second conclusion is that the controller must be robust in order to remain stable, even when large inductance changes occur due to saturation of one core leg.

\section{New topology}

The individual, indicated by a circle in Fig. 9, is chosen for the final design of the close-coupled inductor of the new topology of the converter. The parameters for this design are given in table 4 . In the meanwhile, a design for the output inductor $\mathrm{L}_{\mathrm{x}}$ was made by Spice. The volume of $\mathrm{L}_{\mathrm{x}}$ is about the same as the one for $\mathrm{L}_{\mathrm{ex}}$ because another material, JFE JNEX900, is used instead of the amorphic material. The total volume and power dissipation of the inductive components for the new topology are compared to those of the existing topology in table 5 .

TABLE V. VOLUme AND POWER DisSiPATION INDUCTIVE COMPONENTS

\begin{tabular}{rcccc}
\hline & $\mathbf{3 x L}_{\mathbf{e x}}$ & $\mathbf{L}_{\mathbf{c c l}}+\mathbf{L}_{\mathbf{x}}$ & & Gain \\
\hline Volume & $3 \times 4$ & $6+4$ & $\mathrm{dm}^{3}$ & $16 \%$ \\
Power Dissipation & $3 \times 140 *$ & $110+160 * *$ & $\mathrm{~W}$ & $35 \%$ \\
\hline *measured by FMTC, ${ }^{* *}$ from simulations &
\end{tabular}

From table 5, it is clear that the gain in volume is limited. This limited volume reduction is mainly caused by the imperfect coupling between the core legs. This causes the DC flux, generated by the windings, to not cancel out completely. The fluxes through each core leg, as simulated by the physical model, are shown in Fig. 11. Due to the residual DC flux, only about $70 \%$ of the magnetic material is used. In Fig. 11, the calculations of the proposed physical model of $\mathrm{L}_{\mathrm{ccl}}$ are compared to calculations done with a combination Magnet, for 
full 3D FEM simulations of the inductor, and PLECS, a circuit simulator for power electronics.

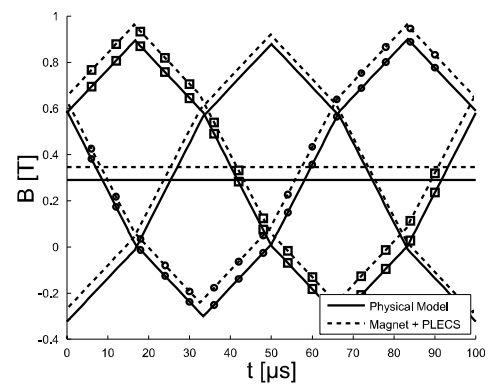

Fig. 11 Magnetic field in each core leg of chosen design for $\mathrm{L}_{\mathrm{ccl}}$, calculated by both the proposed physical model and a combination of Magnet and PLECS

Another factor, that is part of the reason behind the limited volume reduction, is the fact that though the losses of ferrite are lower than those of the amorphic material, (table 1), the thermal conductivity is also less for ferrite (table 3 ).

\section{CONCLUSION}

Using close-coupled inductors instead of separate inductors in interleaved converters can lead to reduction in volume and power dissipation. However, this depends greatly on the chosen materials and a detailed physical model, taking into account electric, magnetic and heat effects, is necessary. Creating such a model and using it to find optimal designs for the inductor is explained in this paper with a specific converter as an example.

A disadvantage of using close-coupled inductors is the controllability of the converter. Because of the cancellation of the DC flux in the core, it is important that the measurement and control system of the converter can keep the unbalance in average phase current within limits as discussed in chapter V.B.

The method described in this paper can be easily adapted to design other types of inductors, e.g. transformers. With a more advanced core model the method can also be extended to inductors with large DC components in the magnetic flux, e.g. single inductors. But this requires extra measurements on the magnetic materials under consideration [11].

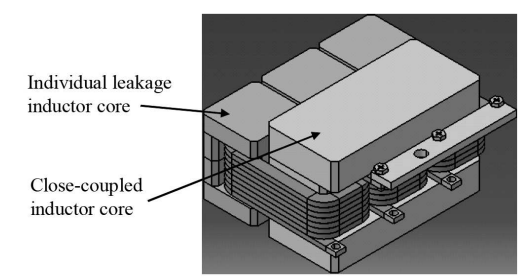

Fig. 12 Three-phase integrated close-coupled inductor [2]

Based on the discussion in chapter V.C, where the main reason of the low volume reduction turned out to be the bad coupling of the windings, another type of close-coupled inductors could be investigated. This type is shown in Fig. 12 and integrates the close-coupled inductor with the output inductor. Bad coupling between the windings is introduced and used to eliminate the output inductor. An additional advantage could be the controllability of the converter as every phase has its own inductor. The main challenge will be to make a good reluctance model of the magnetic core of the integrated closecoupled inductor. Afterwards, the same design procedure as explained in this paper can be used.

\section{ACKNOWLEDGMENT}

The authors would like to express their thanks to the company Spica NV [15] for the support in the development of the design method and for the design of the output inductor.

\section{REFERENCES}

[1] M. Hirakawa, Y. Watanabe, M. Nagano, K. Andoh, S. Nakatomi, S. Hashino, and T. Shimizu, "High Power DC/DC Converter using Extreme Close-Coupled Inductors aimed for Electric Vehicles," The International Power Electronics Conference, Sapporo, Japan, 2010, pp. 2941-2948

[2] M. Hirakawa, M. Nagano, Y. Watanabe, K. Ando, S. Nakatomi, S Hashino, and T. Shimizu, "High Power Density Interleaved DC/DC Converter using a 3-phase Integrated Close-Coupled Inductor Set aimed for Electric Vehicles," IEEE Energy Conversion Congress and Exposition, Atlanta, Georgia, 2010, pp. 2451-2457

[3] C. Rudolph, "Hybrid Drive System of an Industrial Truck Using a Three-Phase DC-DC Converter Feeding Ultra-Capacitors," European Conference on Power Electronics and Applications, Barcelona, Spain, 2009 , pp. 1-10

[4] J. Mülethaler, J. W. Kolar, and A. Ecklebe, "A Novel Approach for 3D Air Gap Reluctance Calculations," International Conference on Power Electronics, The Shilla Jeju, Korea, 2011, pp. 446-452

[5] P. Wallmeier, N. Fröhleke, H. Grotstollen, "Automated optimization of high frequency inductors," Conference of the IEEE Industrial Electronics Society, Aachen, Germany, 1998, pp. 342-347

[6] L. Mandache, D. Topan, M. Iordache, and I.G. Sirbu, "SPICE Model for Effective and Accurate Time Domain Simulation of Power Transformers," International Workshop on Nonlinear Dynamics and Synchronization and International Symposium on Theoretical Electrical Engineering, Klagenfurt, Austria, pp. 1-6

[7] J. Zwysen, and J. Driesen, "Flexible calculation method for airgap and leakage flux reluctances," International Symposium on Electric and Magnetic Fields, Bruges, Belgium, 2013, accepted

[8] J. Zwysen, R. Gelagaev, and J. Driesen, "An Accurate Reluctance Model of Inductive," Conference on the Computation of Electromagnetic Fields, Budapest, Hungary, 2013, submitted

[9] P. Wallmeier, N. Fröhleke, H. Grotstollen, "Improved analytical modeling of conductive losses in gapped high-frequency inductors," IEEE Trans. Ind. Electron., vol. 37, no. 4, pp. 1045-1054

[10] K. Venkatachalam, C.R. Sullivan, T. Abdallah, and H. Tacca, "Accurate Prediction of Ferrite Core Loss with Nonsinusoidal Waveforms Using Only Steinmetz Parameters," IEEE Workshp on Computers in Power Electronics, San Juan, Puerto Rico, 2002, pp. 36-41

[11] J. Mülethaler, J.W. Kolar, and A. Ecklebe, "Loss Modeling of Inductive Components Employed in Power Electronic Systems," International Conference on Power Electronics, The Shilla Jeju, Korea, 2011, pp. 945952

[12] VDI Heat Atlas, 2th ed., VDI-GVC, Düsseldorf, Germany, 2010, pp. 667-669

[13] A. Konak, D.W. Coit, and A.E. Smith, "Multi-objective optimization using genetic algorithms: A tutorial," Reliability Engineering \& System Safety, Vol. 91, No. 9. September 2006, pp. 992-1007

[14] K. Deb, A. Pratap, S. Agarwal, and T. Meyarivan, "A fast and elitist multiobjective genetic algorithm: NSGA-II," IEEE Trans. Evol. Comput., vol. 6, no. 2, April 2002, pp. 182-197

[15] Spica NV, http://www.spica.be 